\title{
Molecular systematics support the revival of Mycobacterium salmoniphilum (ex Ross 1960) sp. nov., nom. rev., a species closely related to Mycobacterium chelonae
}

\section{Correspondence Christopher M. Whipps whippsc@onid.orst.edu}

\author{
Christopher M. Whipps, ${ }^{1}$ W. Ray Butler, ${ }^{2}$ Fazel Pourahmad, ${ }^{3,4}$ \\ Virginia G. Watral ${ }^{1}$ and Michael L. Kent ${ }^{1}$
}

\author{
${ }^{1}$ Center for Fish Disease Research, Department of Microbiology, 220 Nash Hall, Oregon State \\ University, Corvallis, OR 97331-3404, USA \\ ${ }^{2}$ Mycobacteriology Branch, Division of Tuberculosis Elimination, Centers for Disease Control and \\ Prevention, Atlanta, GA, USA \\ ${ }^{3}$ Institute of Aquaculture, University of Stirling, Stirling FK9 4LA, Scotland, UK \\ ${ }^{4}$ School of Veterinary Medicine, Ilam University, PO Box 69315-516, Ilam, Iran
}

\section{INTRODUCTION}

Mycobacteriosis in fish is usually attributed to infections by Mycobacterium chelonae, Mycobacterium fortuitum or Mycobacterium marinum (Belas et al., 1995; Decostere et al.,

\footnotetext{
Abbreviations: ITS, internal transcribed spacer; SSU, small subunit. The GenBank/EMBL/DDBJ accession numbers for the 16S rRNA gene, hsp65 and rpoB sequences of $M$. salmoniphilum strains are D0866764-DQ866770, D0866777-D0866783 and D0866790D0866797 (respectively DQ866768, D0866777 and D0866790 for the type strain).

A tree resulting from Bayesian analysis of $r p o B$ sequences and a strict consensus tree from parsimony analysis of ITS sequences are available as supplementary material with the online version of this paper.
}

2004). However, several recent studies employing DNA sequence data as well as traditional methods of characterization have identified several additional Mycobacterium species that infect fishes (Heckert et al., 2001; Kent et al., 2004; Levi et al., 2003; Rhodes et al., 2003, 2005; Poort et al., 2006; Whipps et al., 2003). Delineation of piscine Mycobacterium species is important not only for animal health but also for human health, as some species are potentially zoonotic. As a case in point, M. marinum infections in humans are often associated with exposure to fish or aquaria (Aubry et al., 2002; Jernigan \& Farr, 2000).

Mycobacteriosis in salmonid fishes has been reported in the literature, but the identity of the species responsible is elusive (Arakawa \& Fryer, 1984; Ashburner, 1977; 
Brocklebank et al., 2003; Bruno et al., 1998; Ross, 1960, 1970). In 1960, Ross described the salmon mycobacterium as a unique species and proposed the name 'Mycobacterium salmoniphilum' (Ross, 1960). However, Gordon \& Mihm (1959) identified these isolates as M. fortuitum. Penso et al. (1962) proposed that only one of the three strains was truly M. fortuitum, and Tsukamura et al. (1967) supported this finding with numerical classification analysis based upon 101 characters and suggested that they 'not be named $M$. fortuitum'. Some of this taxonomic confusion may be explained by the observation that mycobacteria from salmonid fishes exhibit biochemical characteristics of both M. chelonae and M. fortuitum. The inability to distinguish these isolates confidently from $M$. fortuitum resulted in the omission of ' $M$. salmoniphilum' from the Approved Lists of Bacterial Names (Skerman et al., 1980).

Using a broad panel of biochemical analyses, Arakawa \& Fryer (1984) tested additional mycobacterial isolates from salmon, found that they were most like $M$. chelonae and assigned them to ' $M$. chelonae subsp. piscarium'. The subspecies name was later withdrawn (Arakawa et al., 1986), as serological analyses could not separate ' $M$. chelonae subsp. piscarium' from M. chelonae subsp. chelonae or $M$. chelonae subsp. abscessus. Nonetheless, these and other studies (Ashburner, 1977; Brocklebank et al., 2003; Bruno et al., 1998) attributed salmon mycobacteriosis to $M$. chelonae or an M. chelonae-like species.

The body of evidence suggests that these mycobacteria isolated from salmon represent a distinct species that is similar to M. chelonae or M. fortuitum. Therefore, we propose that the name ' $M$. salmoniphilum' suggested by Ross (1960) is valid and its revival warranted. We employed molecular and chemical methods in this study to resolve these conflicting data and to clarify the taxonomic position of mycobacteria isolated from salmon.

\section{METHODS}

Bacterial strains. Isolates maintained in our culture collection, obtained from salmonid fishes, described as ' $M$. salmoniphilum' by
Ross (1960) or 'M. chelonae subsp. piscarium' (Arakawa \& Fryer, 1984) and M. chelonae of Bruno et al. (1998) are listed in Table 1. Cultures were grown on solid-phase media normally used for mycobacteria, including Middlebrook 7H10, Löwenstein-Jensen, blood agar or MacConkey agar, and in Middlebrook 7H9 liquid broth, at $28-30{ }^{\circ} \mathrm{C}$. Biochemical analyses were conducted using standard methods (Kent \& Kubica, 1985).

Mycolic acids. Chemical analysis of the mycolic acids was conducted with HPLC for identification of mycobacteria as reviewed by Butler \& Guthertz (2001).

DNA isolation and PCR amplification. DNA was extracted from cultures using the UltraClean microbial DNA isolation kit (MoBio Laboratories). Amplification of target genes by PCR was conducted using standard methods and primers of Kent et al. (2004), Poort et al. (2006), Selvaraju et al. (2005) and Adékambi et al. (2003). DNAs extracted from uninfected fish tissues were used as negative controls and were consistently negative. Amplification products were either purified directly with the QIAquick PCR Purification kit or excised from the gel and purified using the QIAgen Gel Extraction kit (Qiagen). Sequences were obtained directly from amplification products at the Nevada Genomics Center (Reno, NV, USA).

Phylogenetic analysis. Nucleotide sequences of the small-subunit (SSU) rRNA gene from salmonid isolates were aligned to those of other rapidly growing type strains of mycobacteria. Mycobacterium tuberculosis $\mathrm{H}_{37 \mathrm{Rv}^{\mathrm{T}}}$ and Mycobacterium leprae $\mathrm{TN}$ were used as outgroups. With the sequences of the internal transcribed spacer (ITS) and heat-shock protein $65(h s p 65)$ and RNA polymerase $\beta$ subunit $(r p o B)$ genes, analyses focused only on the $M$. chelonae complex, i.e. M. chelonae, M. abscessus, Mycobacterium immunogenum, Mycobacterium massiliense and Mycobacterium bolletii, and other relevant sequences from BLAST matches on GenBank. $M$. fortuitum strains were used as the outgroup based on recent phylogenetic analyses (Adékambi \& Drancourt, 2004; Devulder et al., 2005) and our preliminary analyses. Alignments were created with CLUSTAL_X (Thompson et al., 1997) and edited manually. Gaps were treated as a fifth character state. Parsimony analyses were conducted in PAUP*4.01 (Swofford, 1998). Maximum-parsimony analysis employed a heuristic search with 10 repetitions of random sequence addition and tree bisection and reconnection branch swapping. Bootstrap confidence values were calculated with a heuristic search using simple sequence addition and 100 replicates. Bayesian analyses were conducted in MrBayes (Ronquist \& Huelsenbeck, 2003) under a general time-reversible (GTR) model, with $10^{6}$ generations, tree sampling every 100 generations and a burn-

Table 1. Isolates of salmonid mycobacteria examined in this study

\begin{tabular}{|llll|}
\hline Isolate & Year & \multicolumn{1}{c|}{ Location } & \multicolumn{1}{c|}{ Host } \\
\hline AUS & 1969 & Victoria, Australia & Chinook salmon (Oncorhynchus tshawytscha) \\
BAN & 1964 & Oregon, USA & Cutthroat trout (Oncorhynchus clarkii clarkii) \\
ELK & 1981 & Oregon, USA & Chinook salmon (O. tshawytscha) \\
SIL & 1966 & Oregon, USA & Coho salmon (Oncorhynchus kisutch) \\
TRA & 1982 & Oregon, USA & Coho salmon (O. kisutch) \\
MON & 1982 & Montana, USA & Whitefish (Prosopium williamsoni) \\
MT1890 (=NCIMB 13533) & 1998 & Shetland, Scotland, UK & Atlantic salmon (Salmo salar) \\
MT1900 & 1998 & Shetland, Scotland, UK & Atlantic salmon (S. salar) \\
CAR (=ATCC 13756) & 1960 & Washington, USA & Chinook salmon (O. tshawytscha) \\
OR $(=$ ATCC 13757) & 1960 & Washington, USA & Steelhead trout (Oncorhynchus mykiss) \\
SC ${ }^{\mathrm{T}}\left(=\right.$ ATCC $13758^{\mathrm{T}}=\mathrm{DSM} 43276^{\mathrm{T}}{ }^{\mathrm{T}}$ ) & 1960 & Washington, USA & Chinook salmon (O. tshawytscha) \\
\hline
\end{tabular}


in of 100 trees. Distance and maximum-likelihood analyses were also conducted in $\operatorname{PAUP}^{\star} 4.01$; they yielded equivalent results to parsimony and Bayesian analysis and are therefore not shown.

\section{RESULTS AND DISCUSSION}

Phylogenetic analysis of the SSU rRNA gene from type strains of the rapidly growing mycobacteria and of isolates assigned to ' $M$. salmoniphilum' confirmed the affiliation of this species to the M. chelonae complex (Fig. 1) as defined previously (Brown-Elliott \& Wallace, 2002; Adékambi et al., 2004, 2006; Selvaraju et al., 2005). The result was consistent with previous studies that have identified these isolates as M. chelonae based primarily on biochemical analyses (Arakawa \& Fryer, 1984; Brocklebank et al., 2003; Bruno et al., 1998). Some common characteristics within this group are a positive 3 day arylsulfatase test, negative nitrate reductase test and the absence of pigmentation. Differential biochemical characteristics include utilization of glucose or citrate and, highly significantly, a lack of growth at or above $37{ }^{\circ} \mathrm{C}$ (Table 2).

To verify that ' $M$. salmoniphilum' isolates were not phylogenetically intermixed with other members of the $M$. chelonae complex, multiple strains of each species were analysed using DNA sequences from $h s p 65$ (Fig. 2), rpoB (Supplementary Fig. S1 available in IJSEM Online) and the ITS (Supplementary Fig. S2). These analyses consistently revealed that ' $M$. salmoniphilum' is monophyletic. Our analyses included a broad range of isolates, including those from the original description of ' $M$. salmoniphilum' (ATCC 13756, ATCC 13757 and ATCC 13758), those described as 'M. chelonae subsp. piscarium' by Arakawa \& Fryer (1984), identical strains MT1890 and MT1900 (results for MT1890 only are shown) from Atlantic salmon incorrectly assigned to M. chelonae (Bruno et al., 1998) and sequences obtained independently of our study from isolate SOL 803 from salmon in a hatchery in eastern Canada (GenBank accession no. AY489137) (Fig. 1). One of the original isolates of Ross (1960), ATCC 13756, was more like M. fortuitum by DNA sequencing, consistent with the observations of Penso et al. (1962) that one of Ross's isolates was M. fortuitum. These data also illustrated that more than one species of Mycobacterium may infect salmon. Indeed, Mycobacterium neoaurum has also been reported from salmon (Roberts, 2001).

Other species within this complex tended to form wellsupported clades in all of the analyses with the exception of the M. abscessus clade, which was rendered paraphyletic by the addition of M. massiliense and M. bolletii (Fig. 2). Estimates of phylogeny of the $M$. chelonae complex varied

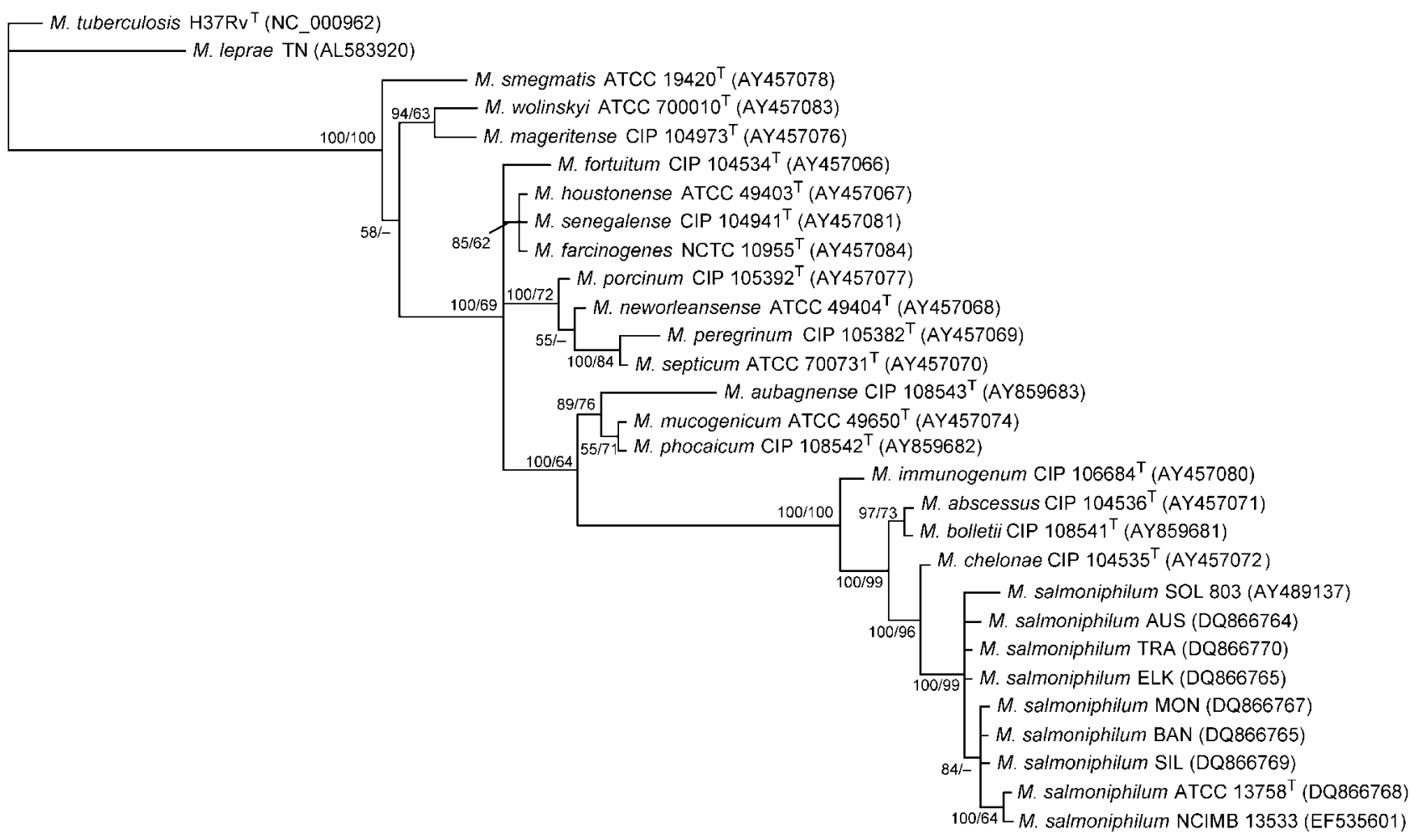

Fig. 1. Tree resulting from Bayesian phylogenetic analysis of SSU (16S) rRNA gene sequences from strains of ' $M$. salmoniphilum' and other rapidly growing mycobacteria. GenBank accession numbers and strain designations are provided. Numbers at nodes are percentage clade credibility values/bootstrap confidence values from parsimony analysis; -, less than $50 \%$. 
Table 2. Biochemical characteristics of salmonid mycobacteria and related species

Related species are abbreviated as follows: Mch, M. chelonae; Mab, M. abscessus; Mim, M. immunogenum; Mma, M. massiliense; Mfo, M. fortuitum. Data were compiled from Ross (1960), Arakawa \& Fryer (1984), Adékambi et al. (2004) and Schinsky et al. (2004). Growth temperature was determined on Middlebrook 7H10, Löwenstein-Jensen, Sauton or Ogawa media. ND, Not done. All mycobacteria shown are positive for growth at 24 or 25 and $30{ }^{\circ} \mathrm{C}$ and negative for growth at 42 and $45{ }^{\circ} \mathrm{C}$.

\begin{tabular}{|c|c|c|c|c|c|c|c|c|c|c|c|c|c|}
\hline Characteristic & $\begin{array}{l}\text { ATCC } \\
13756\end{array}$ & $\begin{array}{l}\text { ATCC } \\
13757\end{array}$ & $\begin{array}{c}\text { ATCC } \\
13758^{T}\end{array}$ & BAN & ELK & SIL & TRA & MON & Mch & Mab & Mim & Mma & Mfo \\
\hline \multicolumn{14}{|l|}{ Utilization of: } \\
\hline Glucose & + & + & + & + & + & + & + & + & - & - & - & - & + \\
\hline Citrate & + & + & + & + & + & + & + & + & + & - & - & - & + \\
\hline Nitrate reductase & - & - & - & - & - & - & - & - & - & - & - & - & + \\
\hline Tolerance of $5 \% \mathrm{NaCl}$ & ND & ND & ND & - & - & - & - & - & - & + & - & + & + \\
\hline Growth at $37{ }^{\circ} \mathrm{C}$ & - & - & - & - & - & - & - & - & + & + & + & + & + \\
\hline
\end{tabular}

depending on the gene analysed, as illustrated by the unstable position of ' $M$. salmoniphilum' in these trees. Analyses of the SSU rRNA gene and $r p o B$ suggested that ' $M$. salmoniphilum' is sister to $M$. chelonae (Fig. 1 and Supplementary Fig. S1), whereas hsp65 analysis showed $M$. immunogenum to be the nearest neighbour (Fig. 2) and, with ITS analysis (Supplementary Fig. S2), M. abscessus was the sister species. Although a consensus cannot be established, all analyses supported ' $M$. salmoniphilum' as an independent lineage, as opposed to a subset of another species.
Sequence similarity between members of the $M$. chelonae complex and ' $M$. salmoniphilum' was high in the SSU rRNA gene (98.6-99.6\%) and progressively lower in the hsp65 (92.0-96.7\%), rрoB (92.2-95.8\%) and ITS (86.3$95.9 \%$ ) sequences. Intraspecifically, DNA sequences of ' $M$. salmoniphilum' isolates from geographically distant locales in eastern and western North America, Australia and Europe possessed a minimum DNA sequence similarity for each gene region as follows: SSU rRNA gene (99.8\%), hsp65 (97.7\%), rpoB (98.0\%) and ITS (98.7\%).

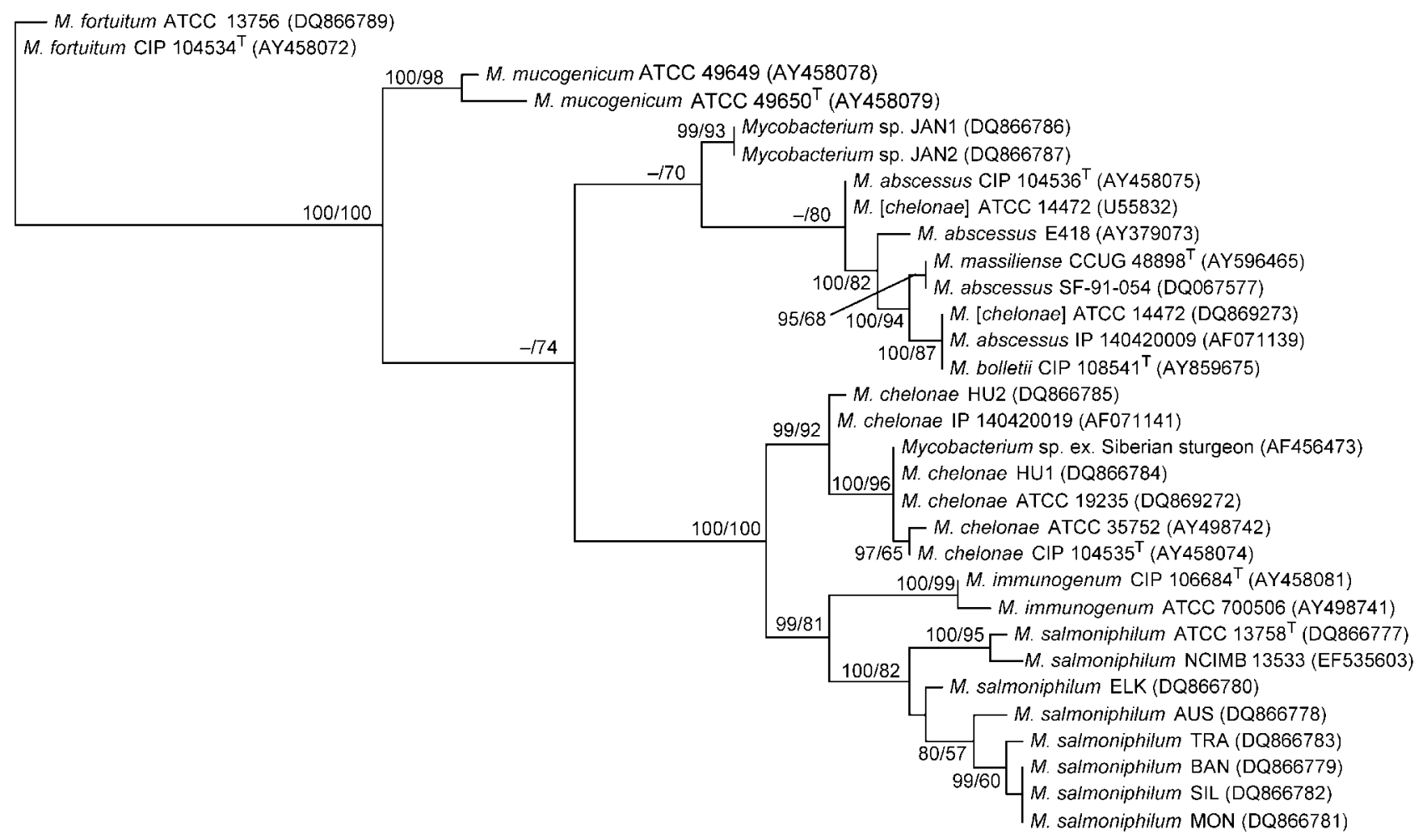

Fig. 2. Tree resulting from Bayesian phylogenetic analysis of $h s p 65$ gene sequences from strains of 'M. salmoniphilum' and other members of the M. chelonae complex. See legend to Fig. 1 for other details. 
Two-dimensional TLC of cell-wall mycolic acids of ' $M$. salmoniphilum' by Arakawa \& Fryer (1984) suggested similarities to M. chelonae and M. abscessus, having $\alpha$ and $\alpha^{\prime}$ mycolates. Isolates lacked the epoxy mycolates found in M. fortuitum. HPLC patterns of mycolic acids confirmed that the study isolates shared some characteristics with the $M$. chelonae complex and with the $M$. fortuitum complex (Fig. 3). However, new HPLC analysis of cell-wall mycolic acids of 'M. salmoniphilum' isolates visually demonstrated two separate peak groups, lacking the middle peaks found

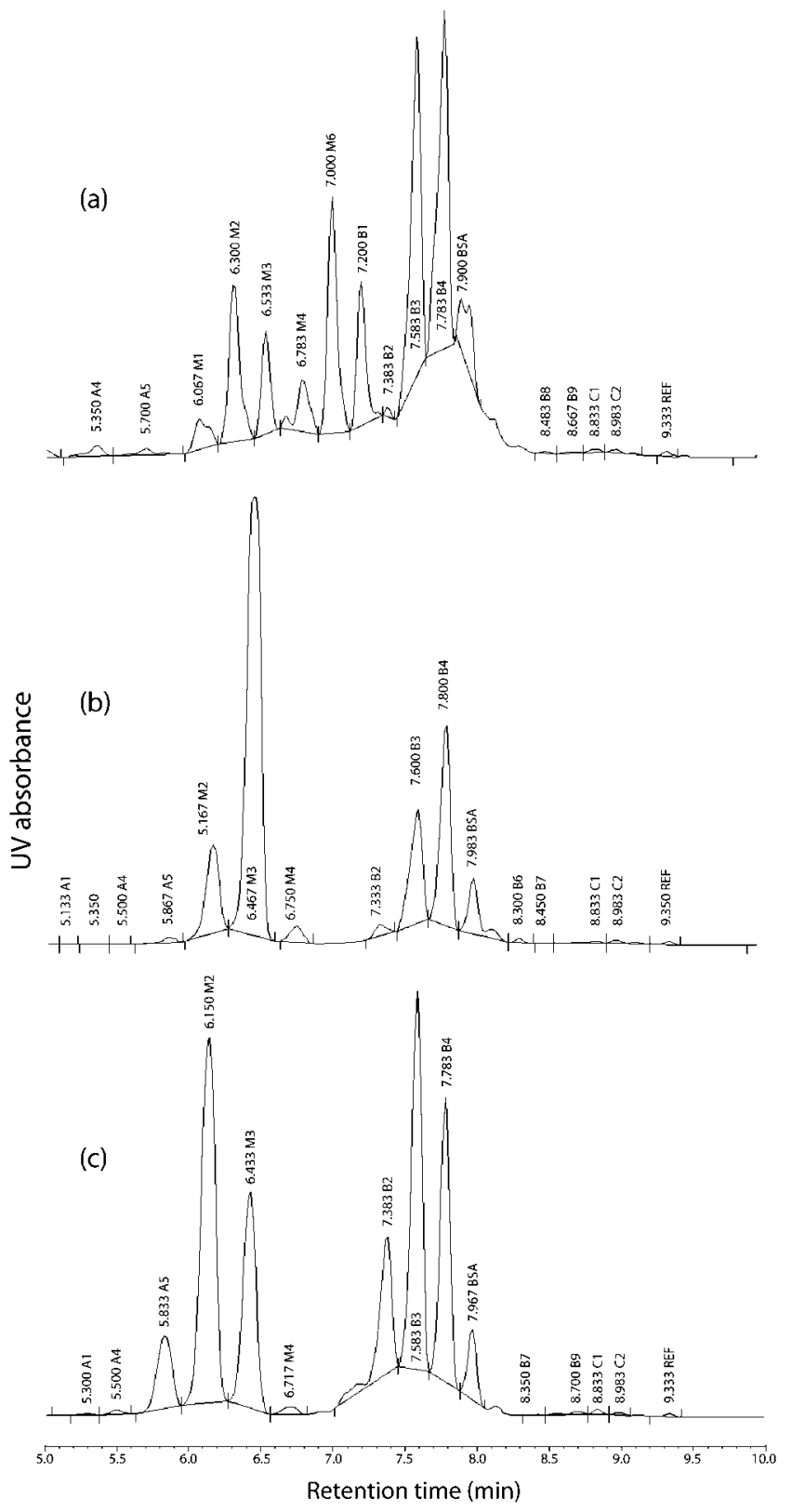

Fig. 3. Mycolic acid HPLC profiles for M. fortuitum ATCC $6841^{\top}$ (a), M. abscessus ATCC $19977^{\top}$ (b) and strain ATCC $13758^{\top}$ (M. salmoniphilum sp. nov., nom. rev.) (c). in M. fortuitum (Fig. 3a; Butler \& Kilburn, 1990). Although the HPLC patterns were similar to that of M. fortuitum (Fig. 3a), the number of mycolic acid peaks and the peak heights were different for ' $M$. salmoniphilum' (Fig. 3c). Thus, the distribution of mycolic acids supported the separation of the study isolates from species within the $M$. chelonae complex and M. fortuitum.

We conclude that ' $M$. salmoniphilum' is a pathogen of salmonid fishes that is phylogenetically and physiologically distinct from other members of the M. chelonae complex. The description of the salmon mycobacterium by Ross (1960) was consistent with our findings, but the name ' $M$. salmoniphilum' has no current standing in nomenclature. Thus, in accordance with Rules 28a and 33a, b and c of the International Code of Nomenclature of Bacteria (Lapage et al., 1992), we propose the revival of this name based on our analysis of Ross's original isolates and other wellidentified strains and ascribe them to Mycobacterium salmoniphilum sp. nov., nom. rev. We designate ATCC $13758^{\mathrm{T}}$ as the type strain based on the following criteria. Ross (1960) submitted three isolates to the ATCC; two were identified in this study as M. salmoniphilum (ATCC 13757 and ATCC $13758^{\mathrm{T}}$ ) by DNA sequencing, and one was confirmed as $M$. fortuitum (ATCC 13756). Strain ATCC $13758^{\mathrm{T}}$ is also available from the DSMZ as DSM $43276^{\mathrm{T}}$ and therefore satisfies the ICSP requirement for deposit of type strains in two collections in different countries.

\section{Description of Mycobacterium salmoniphilum (ex Ross 1960) sp. nov., nom. rev.}

Mycobacterium salmoniphilum (sal.mo.ni.phi'lum. L. n. salmo -onis a salmon; Gr. adj. philos loving; N.L. neut. adj. salmoniphilum salmon-loving).

The description is as given by Ross (1960) and also follows the descriptions of ' $M$. chelonae subsp. piscarium' Arakawa \& Fryer (1984) and 'Salmoniphilum' strains of M. fortuitum (Tsukamura et al., 1967). Cells are acid-fast bacilli, consistent with species of the genus Mycobacterium. Growth occurs on Middlebrook 7H10 agar, blood agar, MacConkey agar and Löwenstein-Jensen slants, forming cream-coloured, smooth, shiny colonies, visible after 46 days. Following incubation periods exceeding 10 days, colonies tend to appear waxy, with an irregular border and 'fried egg' morphology. Growth is observed at room temperature $\left(20^{\circ} \mathrm{C}\right)$ and with incubation at 28 to $30{ }^{\circ} \mathrm{C}$. Weak or delayed growth may occur at $10{ }^{\circ} \mathrm{C}$, and no growth is observed at or above $37{ }^{\circ} \mathrm{C}$. Bacilli are generally slender and straight or slightly curved, with some short and thick. Dimensions range from 1 to $4 \mu \mathrm{m}$ in length and 0.25 to $0.6 \mu \mathrm{m}$ in width. Isolates have been recovered from infected salmonid fishes (although there may be other susceptible species), found throughout the viscera and predominantly in the kidney. Closely related species are members of the $M$. chelonae complex, i.e. M. chelonae, M. abscessus, $M$. immunogenum, M. massiliense and M. bolletii, sharing the 
characteristics of a positive 3 day arylsulfatase test, negative nitrate reductase test and the absence of pigmentation. Strains can be distinguished from these species by a positive test for glucose utilization and by DNA sequences. Sequence analysis of the SSU rRNA gene, $h s p 65, r p o B$ and ITS regions shows that isolates are phylogenetically and consistently distinct from other members of the M. chelonae complex. Mycolic acid HPLC patterns are visually distinct, forming two clusters of mycolates.

The type strain is strain $\mathrm{SC}^{\mathrm{T}}$ (=ATCC $13758^{\mathrm{T}}=\mathrm{DSM}$ $43276^{\mathrm{T}}$ ), isolated from Chinook salmon (Oncorhynchus tshawytscha) at the Spring Creek fish hatchery in Washington state, USA.

\section{ACKNOWLEDGEMENTS}

We thank José Luis Tejedor del Real for the sequencing of ATCC 13756 and Nadege Charles at the CDC Mycobacteriology laboratory for the HPLC patterns. The authors are grateful for the services of Nevada Genomics Center, which is supported in part by a grant from the Nevada IDeA Network of Biomedical Research Excellence (2 P20 RR016463).

\section{REFERENCES}

Adékambi, T. \& Drancourt, M. (2004). Dissection of phylogenetic relationships among 19 rapidly growing Mycobacterium species by $16 \mathrm{~S}$ rRNA, hsp65, sodA, recA and rpoB gene sequencing. Int J Syst Evol Microbiol 54, 2095-2105.

Adékambi, T., Colson, P. \& Drancourt, M. (2003). rpoB-based identification of nonpigmented and late-pigmenting rapidly growing mycobacteria. J Clin Microbiol 41, 5699-5708.

Adékambi, T., Reynaud-Gaubert, M., Greub, G., Gevaudan, M. J., La Scola, B., Raoult, D. \& Drancourt, M. (2004). Amoebal coculture of "Mycobacterium massiliense" sp. nov. from the sputum of a patient with hemoptoic pneumonia. J Clin Microbiol 42, 5493-5501.

Adékambi, T., Berger, P., Raoult, D. \& Drancourt, M. (2006). rpoB gene sequence-based characterization of emerging non-tuberculous mycobacteria with descriptions of Mycobacterium bolletii sp. nov., Mycobacterium phocaicum sp. nov. and Mycobacterium aubagnense sp. nov. Int J Syst Evol Microbiol 56, 133-143.

Arakawa, C. K. \& Fryer, J. L. (1984). Isolation and characterization of a new subspecies of Mycobacterium chelonei infectious for salmonid fish. Helgolander Meeresunters 37, 329-342.

Arakawa, C. K., Fryer, J. L. \& Sanders, J. E. (1986). Serology of Mycobacterium chelonei isolated from salmonid fish. J Fish Dis 9, 269-271.

Ashburner, L. D. (1977). Mycobacteriosis in hatchery-confined chinook salmon (Oncorhynchus tshawytscua Walbaum) in Australia. J Fish Biol 10, 523-528.

Aubry, A., Chosidow, O., Causmes, E., Jermoe, R. \& Cambau, E. (2002). Sixty-three cases of Mycobacterium marinum infection. Arch Intern Med 162, 1746-1752.

Belas, R., Faloon, P. \& Hannaford, A. (1995). Potential applications of molecular biology to the study of fish mycobacteriosis. Annu Rev Fish Dis 5, 133-173.

Brocklebank, J., Raverty, S. \& Robinson, J. (2003). Mycobacteriosis in Atlantic salmon farmed in British Columbia. Can Vet J 44, $486-489$.
Brown-Elliott, B. A. \& Wallace, R. J., Jr (2002). Clinical and taxonomic status of pathogenic nonpigmented or late-pigmenting rapidly growing mycobacteria. Clin Microbiol Rev 15, 716-746.

Bruno, D. W., Griffiths, J., Mitchell, C. G., Wood, B. P., Fletcher, Z. J., Drobniewski, F. A. \& Hastings, T. S. (1998). Pathology attributed to Mycobacterium chelonae infection among farmed and laboratoryinfected Atlantic salmon Salmo salar. Dis Aquat Organ 33, 101-109.

Butler, W. R. \& Guthertz, L. S. (2001). Mycolic acid analysis by highperformance liquid chromatography for identification of Mycobacterium species. Clin Microbiol Rev 14, 704-726.

Butler, W. R. \& Kilburn, J. O. (1990). High-performance liquid chromatography patterns of mycolic acids as criteria for identification of Mycobacterium chelonae, Mycobacterium fortuitum, and Mycobacterium smegmatis. J Clin Microbiol 28, 2094-2098.

Decostere, A., Hermans, K. \& Haesebrouck, F. (2004). Piscine mycobacteriosis: a literature review covering the agent and the disease it causes in fish and humans. Vet Microbiol 99, 159-166.

Devulder, G., Perouse de Montclos, M. \& Flandrois, J. P. (2005). A multigene approach to phylogenetic analysis using the genus Mycobacterium as a model. Int J Syst Evol Microbiol 55, 293-302.

Gordon, R. E. \& Mihm, J. M. (1959). A comparison of four species of mycobacteria. J Gen Microbiol 21, 736-748.

Heckert, R. A., Elankumaran, S., Milani, A. \& Baya, A. (2001). Detection of a new Mycobacterium species in wild striped bass in the Chesapeake Bay. J Clin Microbiol 39, 710-715.

Jernigan, J. A. \& Farr, B. M. (2000). Incubation period and sources of exposure for cutaneous Mycobacterium marinum infection: case report and review of the literature. Clin Infect Dis 31, 439-443.

Kent, P. T. \& Kubica, G. P. (1985). Public Health Mycobacteriology: a Guide for the Level III Laboratory. Atlanta, GA: US Dept of Public Health \& Human Services, Centers for Disease Control.

Kent, M. L., Whipps, C. M., Matthews, J. L., Florio, D., Watral, V., Bishop-Stewart, J. K., Poort, M. \& Bermudez, L. (2004). Mycobacteriosis in zebrafish (Danio rerio) research facilities. Comp Biochem Physiol C Toxicol Pharmacol 138, 383-390.

Lapage, S. P., Sneath, P. H. A., Lessel, E. F., Skerman, V. B. D., Seeliger, H. P. R. \& Clark, W. A. (editors) (1992). International Code of Nomenclature of Bacteria (1990 Revision). Bacteriological Code. Washington, DC: American Society for Microbiology.

Levi, M. H., Bartell, J., Gandolfo, L., Smole, S. C., Costa, S. F., Weiss, L. M., Johnson, L. K., Osterhout, G. \& Herbst, L. H. (2003). Characterization of Mycobacterium montefiorense sp. nov., a novel pathogenic Mycobacterium from moray eels that is related to Mycobacterium triplex. J Clin Microbiol 41, 2147-2152.

Penso, G., Castelnuova, G. \& Morellini, M. (1962). Revisione della specie Mycobacterium minetti (Penso et al., 1951). Ann Ist Carlo Forlanini 22, 145-188 in Italian

Poort, M. J., Whipps, C. M., Watral, V. G., Font, W. F. \& Kent, M. L. (2006). Description of a Mycobacterium species in non-native poeciliids in Hawaii using DNA sequences. J Fish Dis 29, 181-185.

Rhodes, M. W., Kator, H., Kotob, S., van Berkum, P., Kaattari, I., Vogelbein, W., Quinn, F., Floyd, M. M., Butler, W. R. \& Ottinger, C. A. (2003). Mycobacterium shottsii sp. nov., a slowly growing species isolated from Chesapeake Bay striped bass (Morone saxatilis). Int $J$ Syst Evol Microbiol 53, 421-424.

Rhodes, M. W., Kator, H., McNabb, A., Deshayes, C., Reyrat, J. M., Brown-Elliott, B. A., Wallace, R., Jr, Trott, K. A., Parker, J. M. \& other authors (2005). Mycobacterium pseudoshottsii sp. nov., a slowly growing chromogenic species isolated from Chesapeake Bay striped bass (Morone saxatilis). Int J Syst Evol Microbiol 55, 1139-1147. 
Roberts, R. J. (2001). The bacteriology of teleosts. In Fish Pathology, 3rd edn, pp. 297-331. Edited by R. J Roberts. Toronto: W. B. Saunders.

Ronquist, F. \& Huelsenbeck, J. P. (2003). MrBayes 3: Bayesian phylogenetic inference under mixed models. Bioinformatics 19, 1572-1574.

Ross, A. J. (1960). Mycobacterium salmoniphilum sp. nov. from salmonid fishes. Am Rev Respir Dis 81, 241-250.

Ross, A. J. (1970). Mycobacteriosis among salmonid fishes. In $A$ Symposium on Diseases of Fishes and Shellfishes, Special Publication No. 5. Edited by S. F. Snieszko. Washington, DC: American Fisheries Society.

Schinsky, M. F., Morey, R. E., Steigerwalt, A. G., Douglas, M. P., Wilson, R. W., Floyd, M. M., Butler, W. R., Daneshvar, M. I., BrownElliott, B. A. \& other authors (2004). Taxonomic variation in the Mycobacterium fortuitum third biovariant complex: description of Mycobacterium boenickei sp. nov., Mycobacterium houstonense sp. nov., Mycobacterium neworleansense sp. nov. and Mycobacterium brisbanense sp. nov. and recognition of Mycobacterium porcinum from human clinical isolates. Int J Syst Evol Microbiol 54, 1653-1667.
Selvaraju, S. B., Khan, I. U. \& Yadav, J. S. (2005). A new method for species identification and differentiation of Mycobacterium chelonae complex based on amplified hsp65 restriction analysis (AHSPRA). Mol Cell Probes 19, 93-99.

Skerman, V. B. D., McGowan, V. \& Sneath, P. H. A. (editors) (1980). Approved lists of bacterial names. Int J Syst Bacteriol 30, 255-420.

Swofford, D. L. (1998). PAUP*. Phylogenetic Analysis Using Parsimony ( ${ }^{*}$ and Other Methods), version 4. Sunderland, MA: Sinauer Associates.

Thompson, J. D., Gibson, T. J., Plewniak, F., Jeanmougin, F. \& Higgins, D. G. (1997). The CLUSTAL_X windows interface: flexible strategies for multiple sequence alignment aided by quality analysis tools. Nucleic Acids Res 25, 4876-4882.

Tsukamura, M., Tsukamura, S. \& Mizuno, S. (1967). Numerical taxonomy of Mycobacterium fortuitum. Jpn J Microbiol 11, 243-252.

Whipps, C. M., Watral, V. G. \& Kent, M. L. (2003). Characterization of a Mycobacterium sp. in rockfish, Sebastes alutus (Gilbert) and Sebastes reedi (Westrheim \& Tsuyuki), using rDNA sequences. J Fish Dis 26, 241-245. 